|Araştırma Makalesi / Research Article|

\title{
Heinrich Ullrich Müzik Sistemi: Ulwila Renkli Nota Sistemi ve Çalgıları ile Müzik Eğitimi ${ }^{1}$ \\ Music System of Heinrich Ullrich: Music Education with Ulwila Colorful Note System and Instruments
}

\section{Nezihe Şentürk², Yiğit Erkoç ${ }^{3}$, Tuğba Çağlak Eker ${ }^{4}$}

Anahtar Kelimeler
Heinrich Ullrich
müzik eğitimi
özel eğitim
Ulwila

Keywords

Heinrich Ullrich

music education

special education

Ulwila

Başvuru Tarihi/Received

27.11.2019

Kabul Tarihi /Accepted

26.06.2020
Öz

Heinrich Ullrich'in 1970 'li yıllarda özel eğitim yaklaşımı ile geliştirdiği, renkli nota sistemine dayanan Heinrich Ullrich'in Müzik Sistemi bu araştırmanın konusunu oluşturmaktadır. Ullrich'in renkli şekillerle oluşturduğu nota sistemi ve bunu destekleyen çalgılarla uygulanan müzik öğretim yaklaşımı, yalnızca engelli bireyler için değil erken müzik eğitimi için de kullanılabilmektedir. Özel eğitim yaklaşımları arasında büyük öneme sahip olduğu düşünülen Heinrich Ullrich'in Müzik Sistemi'nin Türkiye'de tanınmıyor olması bu araştırmanın problem durumunu oluşturmaktadır. Buradan hareketle araştırmanın amacı, engelli çocuklar ve yetişkinler için geliştirilmiş bu müzik öğretim yaklaşımını tanıtmaktır. Betimsel bir çalışma olan bu araştırmada verilere doküman incelemesi yolu ile ulaşılmış ve toplanan veriler betimsel analiz yapılarak yorumlanmıştır.

\section{Abstract}

Heinrich Ullrich's Music System which developed with special education approach by Heinrich Ullrich 1970s is the subject of this research. This musical teaching approach, applied by Ullrich's note system with colorful shapes and the supporting instruments, can be used not only for disabled people but also for early music education. The fact that Heinrich Ullrich's Music System is not recognized in Turkey, which is thought to have a great importance among special education approaches, constitutes the problem of this research. The aim of this research is to introduce this music teaching approach developed for disabled children and adults. In this research which is a descriptive study, the data were reached via document review and the collected data were interpreted by descriptive analysis.

\footnotetext{
${ }^{1}$ Bu çalışmanın bir kısmı 2017 Temmuz ayında Kıbrıs'ta gerçekleştirilen Uluslararası 3. İpek Yolu Müzik Konferansı'nda bildiri olarak sunulmuştur.

2 Sorumlu Yazar, Gazi Üniversitesi, Gazi Eğitim Fakültesi, Müzik Eğitimi Anabilim Dalı, Ankara, TÜRKiYE; https://orcid.org/ 0000-0002-9117-4764

${ }^{3}$ Cemal Bozkurt Anadolu Lisesi, Kayseri, TÜRKiYE; https://orcid.org/0000-0003-3003-3236

${ }^{4}$ Çankırı Karatekin Üniversitesi, Güzel Sanatlar Fakültesi, Müzik Bölümü, Çankırı, TÜRKiYE; https://orcid.org/0000-0003-1062-4645
}

Alıntı/Citation: Şentürk, N., Erkoç, Y., \& Çağlak Eker, T. (2020). M Heinrich Ullrich Müzik Sistemi: Ulwila Renkli Nota Sistemi ve Çalgıları ile Müzik Eğitimi. Kastamonu Education Journal, 28(5), 1956-1966. doi: 10.24106/kefdergi.4091 


\section{Extended Abstract}

\section{Introduction}

The aim of this research is to introduce Heinrich Ullrich's Music System, which was developed for children and adults with disabilities. In accordance with this purpose, responses to sub-objective statements were sought: What is the color note system developed by Heinrich Ullrich?, What are the instruments and characteristics of Heinrich Ullrich's music system?, What institutions or organizations implement the Heinrich Ullrich music system? In this study, which is based on the fact that there have been studies on the approaches of music education in the field, there have been no studies on the Ulwila method developed by Heinrich Ullrich, the approach of music in special education, knowledge about Heinrich Ullrich, who developed the method in question; recognition of Ulwila method; recognition of colored note system and instruments and the idea of contributing to music education on special education constitute the importance of research.

\section{Method}

In this section of the study, information about the model of the research, data collection and analysis is given. Descriptive research methods and techniques were used in this qualitative study. This study, in which Ulwila Method is researched and examined, is an example of a case study which is one of the qualitative research methods. In this research, literature was searched through document analysis, data were collected by articles, papers, thesis, books and documents from internet sources that consist about Henrich Ullrich, Ulwila color note system, Ulwila instruments and institutions and organizations which implement this method. The descriptive analysis method was used to analyze the data.

\section{Result and Discussion}

Ulwila in music teaching approach, colored note system is used to play instruments for individuals who have special education. In the colorful musical notes system, the musical notes symbolize with colored circle shapes. In the Ulwila music teaching approach, the notes are placed on a scale from black (C) to yellow color (B) defined on the Do Major scale. Each color represents a different note. However, different shapes used for the same color are used to distinguish the pitch of notes. In other words, the heights of notes of the same color are separated by their shapes Ulwila's music teaching approach uses three octaves, including semitones. Only the shapes with colors show the octave Do1. The black dot in the circle is a lower octave; the white dot in the circle indicates an upper octave.

The instruments used in the Ulwila music teaching approach shows similarity to the instruments used in the Orff-Schulwerk approach. Instruments of this approach are specially developed clavier, percussion, stringed and similar instruments. Color system is also seen in instruments. "These colors, which appear in the score, are also indicated beside the strings, pipes and keys of the special Ulwila instruments. According to Ullrich's method, the children can match a tone with its corresponding color without even knowing the names of the colors" (TóthBakos,. 2016:7). The colored note system and instruments used are also designed to serve this purpose. Some of these instruments are Akkordbrett, Akkordlaute, Bass, Saiten-bassstäbe, Farb-banjo, Mundharmonika, Roehrenglsp, Spießlaute, Steckfloete, Zupfbrett.

The Ulwila music teaching approach is implemented in Tom Mutters Schule in Frankenthal, Germany. Music educaiton and orchestral works were performed by Ullrich in this school, which was founded by Ullrich. In addition, in 1999, the school orchestra contucting by Ullrich, has an album called Lass Die Sonne In Dein Herz (Let the Sun into Your Heart) by Art Voice Records. After Germany, this approach was adopted and implemented in many special education schools in Hungary. In 1991, Anna Vetõ, a special education teacher, introduced the Ulwila approach in Hungary. In 1995, the Ulwila music program for disabled youth and children was introduced. In 1997, the association "A zene mindenkié" (Music for All) and the Budapest Ulwila Orchestra were founded. This orchestra was named Parafonia in 2003. The Parafonia Orchestra was founded In the Ulwila music education approach. This orchestra, which includes children and adults, is important in terms of meeting music and musical development of the individual. Gábor Bajnok is another music teacher who continues music education and orchestral studies in the Ulwila approach "Gábor Bajnok, the music teacher in "Dió" Elemenatry School and leader of the of the 'Dió' Orchestra (consist of children living with intellectual disabilities) have been organizing yearly festival called "Spring Feast of Music" in which 10-12 special orchestra can meet and perform together in every spring since 2005" (Tiszai, 2015).

This study has shown that music education of individuals with special educational needs can be learned by Ulwila approach and instruments. It is understood that it is more encouraging for students to work together with their age groups and teachers. It is known that Ulwila approach is one of the first studies in music education of special education students in Europe. Based on the findings, this study offers to use Ulwila approach in special education and early age music educaiton with the thought of color note system used in Ulwila approach can be applied in preschool education, Ulwila music education approach is the most appropriate approach as it does not pose any problem for individuals who need special education in playing instruments and having music education, hat the basic instruments used in the Orff approach can be adapted to this approach as it will be difficult to make or obtain instruments, behaviors such as group movement, polyphonic music experience and sense of accomplishment can be easily gained through this approach. 


\section{GiRiş}

"Eğitimin her alanında olduğu gibi müzik eğitiminin de ilke ve amaçları eğitimin türüne, düzeyine, süresine ve içeriğine bağlı olarak değişmektedir. Ancak bireyin müzik yaşantısını genişletmek, müziksel algılama yeteneğini geliştirmek, iyi bir müzik dinleyicisi yapmak, çalarak, söyleyerek, araştırarak müziği yaşantısına daha etkin bir şekilde katmak, çok yönlü eleştirel bir müzik kültürü ve anlayışına sahip kılmak gibi temel ilke ve hedeflerin müzik eğitiminin her düzeyinde geçerli olduğu bilinmektedir" (Şentürk, 1998-161).

Bu doğrultuda birçok müzik öğretim yaklaşımı geliştirilmiştir. Bunlar; Dalcroze, Suzuki, Orff-Schulwerk, Kodály olarak sıralanabilir. Bu yaklaşımların dışında farklı teknikler kullanılarak da müzik eğitiminde etkili öğrenme-öğretme sağlanabilir. Ayrıca müzik yalnızca bir okul etkinliği olarak değil bireylerin iletişim kurma, sosyalleşme ve bir nevi bir ifade aracı olarak düşünülebilir. Elbette ki bu davranışsal gelişimler eğitimin bir parçası olarak kabul edilmekte ve müziğin büyük ölçüde etkili olduğu bu süreçte, özellikle özel eğitim alan çocukların gelişiminde büyük önem taşıdığı düşünülmektedir.

Özel eğitimde müzik eğitimine ilişkin İlgili literatür tarandığında Heinrich Ullrich'in Müzik Sistemi'ne rastlanmıştır. "Ulwila Metodu" olarak da bilinen bu metot Alman müzik öğretmeni ve özel eğitimci Heinrich Ullrich tarafından geliştirilmiştir. "Onun benzersiz pedagojik müzik yaklaşımı, engelli çocukların melodi çalamayacağı görüşüne karşı olarak, engelli çocukların müzik eğitimi için öngörülmüştür" (Bakos, 2014-3). Ullrich, temel eğitim olarak müzik eğitiminin uygulandığı Tom Mutters Schule'nin kurucusudur. Tam zamanlı bir özel eğitim okulu olan bu okul Almanya'nın Frankenthal şehrinde bulunmaktadır. Ullrich Tom Mutters Schule'de müzik yaklaşımını uygulamış ve engelli bireylerden oluşan bir orkestra oluşturmuştur. Illk olarak Almanya'da kullanılan bu yaklaşım müzik eğitimcisi Anna Vetõ tarafından Macaristan'da da tanınmış ve benimsenmiştir. Birçok özel eğitim okulunda Ulwila yaklaşımı kullanılarak müzik eğitimi verilmekte ve orkestra çalışmaları yapılmaktadır.

"Heinrich Ullrich şarkı söylemek, müzik dinlemek, çalgı performansı, dans, doğaçlama, kompozisyon ve çalgı yapımı gibi yedi farklı müzik eğitimi alanını içeren kapsamlı bir yöntem geliştirmiştir. Yaklaşımı Kodály'nin ilköğretim döneminde şarkı söyleme yaklaşımına benzerdir. Bu çalışma, onun yaklaşımında renk sistemi ve orkestra müziğine odaklanmaktadır" (Tiszai, 2015).

Ulwila Metodu, Ullrich'in geliştirmiş olduğu renkli nota sistemini ve özel çalgıları kapsamaktadır. Çalgılar, engelli bireylerin profesyonel ve sosyal rehabilitasyonunu amaçlayarak kurulan bir atölye olan Landshuter Werkstätten şirketi ile işbirliği yapılarak Heinrich Ullrich ve müzik eğitimcisi Hermann Josef Wilbert tarafından geliştirilmiş, çalgıların üretimini Landshuter Werkstätten şirketi gerçekleştirmiştir. Ulwila ismi de ortaklaşa yapılan bu çalışmadan gelmektedir. Heinrich Ullrich, Hermann Josef Wilbert ve Landshuter Werkstätten şirketinin isimlerinin ilk hecelerinin birleşmesi ile oluşmuştur. UL: Ullrich; WI: Wilbert; LA: Landshuter Werkstätten (Manhart, 2007:45).

Özel eğitimde müzik eğitimi yaklaşımı olan Ulwila Metodu'nun müzik eğitimi yaklaşımları arasında çok bilinmiyor oluşu araştırmanın problem durumunu oluşturmaktadır.

Bu araştırmanın amacı, engelli çocuklar ve yetişkinler için geliştirilmiş olan Heinrich Ullrich'in Müzik Sistemi'ni tanıtmaktır. Bu amaç doğrultusunda aşağıdaki alt amaç ifadelerine yanıt aranmıştır;

Heinrich Ullrich'in geliştirdiği renkli nota sistemi nasıldır?

Heinrich Ullrich'in müzik sisteminde kullanılan çalgılar ve özellikleri nelerdir?

Heinrich Ullrich müzik sistemini uygulayan kurum veya kuruluşlar nelerdir?

Alana yönelik müzik eğitimi yaklaşımlarına ilişkin çalışmaların bulunmasına karşın özel eğitimde müzik yaklaşımı olan Heinrich Ullrich'in geliştirdiği Ulwila Metodu ile ilgili bir çalışmaya rastlanılmamış olmasından yola çıkılan bu çalışmada, söz konusu metodu geliştiren Heinrich Ullrich hakkında bilgi sahibi olunması; Ulwila Metodu'nun tanınması; renkli nota sistemi ve çalgıların tanınması ile özel eğitimde müzik eğitimine katkı sağlanabileceği düşüncesi araştırmanın önemini oluşturmaktadır.

\section{YÖNTEM}

Araştırmanın bu bölümünde; araştırmanın modeli, verilerin toplanması ve analizi ile ilgili bilgilere yer verilmiştir.

\section{Araştırmanın Modeli}

Nitel bir çalışma olan bu araştırmada betimsel araştırma yöntem ve teknikleri kullanılmıştır. "Nitel araştırma; çeşitli olay ve olguların, bulundukları ortamlar içerisinde, detaylı bir inceleme sonucu keşfedilmesi, anlaşılması ve yorumlanması esasına dayanan bilimsel bir çalışmadır" (Tıkaç, 2015:360). Ulwila Metodu'nun araştırılıp incelendiği bu çalışma nitel araştırma yöntemlerinden durum çalışmasına örnektir. "Durum çalışması, olayların/durumların içerisindeki dinamikleri anlamaya odaklı bir araştırma stratejisidir" (Eisenhardt, 1989:534).

\section{Verilerin Toplanması}

Bu araştırmada doküman inceleme yoluyla literatür taranmış, özel eğitimde müzik eğitiminden yola çıkılarak Heinrich Ullrich, Ulwila renkli nota sistemi, Ullrich'in renkli nota sisteminde yazmış olduğu kitapları, Ulwila çalgıları ile bu sistemi uygulayan kurum ve kuruluşlarla ilgili verilere, bilimsel makale, bildiri, tez, kitap ve internet kaynaklarından doküman incelemesi yolu ile ulaşılmıştır. "Araştırma kapsamında incelenen konuyla ilgili olgu ve olaylar hakkında bilgi içeren yazılı belgelerin analiz edilmesiyle veri sağlanmasına doküman incelemesi denilmektedir" (Karataş, 2015: 72). 


\section{Verilerin Analizi}

Araştırma kapsamında elde edilen verilerin analizi betimsel analiz yöntemi ile yapılış̧ırı. "Bu tür analizde amaç, elde edilen bulguları düzenlenmiş ve yorumlanmış bir biçimde okuyucuya sunmaktır" (Yıldırım ve Şimşek, 2016: 239).

\section{BULGULAR}

Araştırmada elde edilen bulgular araştırmanın alt amaçları doğrultusunda aşağıda sunulmuştur.

\section{Heinrich Ullrich'in Geliştirdiği Renkli Nota Sistemi}

Ulwila müzik öğretim yaklaşımında özel eğitim alan bireylerin çalgı çalabilmeleri amacıyla renkli nota sistemi kullanılmaktadır. Renkli nota sisteminde notalar renkli daire şekilleri ile sembolize etmektedir. Ulwila müzik öğretim yaklaşımında notalar, Do Majör dizisi üzerinden tanımlanan (do notası) siyah renkten, (si notası) sarı renge doğru bir skala içerisinde yer almaktadır. Her renk farkı bir notayı temsil etmektedir.

Bununla birlikte aynı renk için kullanılan farklı şekiller ise notaların yüksekliklerinin ayırt edilmesinde kullanılır. Başka bir deyişle aynı renge sahip notaların yükseklikleri, şekilleri ile birbirinden ayrıımaktadır. Ulwila müzik öğretim yaklaşımında ara sesler de dahil olmak üzere üç oktav kullanılmaktadır. Sadece renklerin olduğu şekiller Do1 oktavını göstermektedir. Çember içerisinde yer alan siyah nokta, bir alt oktavı; çember içerisinde yer alan beyaz nokta ise bir üst oktavı göstermektedir.

"Ara seslerin kullanımı ise, her iki notanın renklerinin çemberi eşit bir şekilde bölmesi ile oluşmaktadır" (Tóth-Bakos, 2013). içerisinde iki farklı renk olan notalar, o renklere denk gelen notaların ara sesleridir.

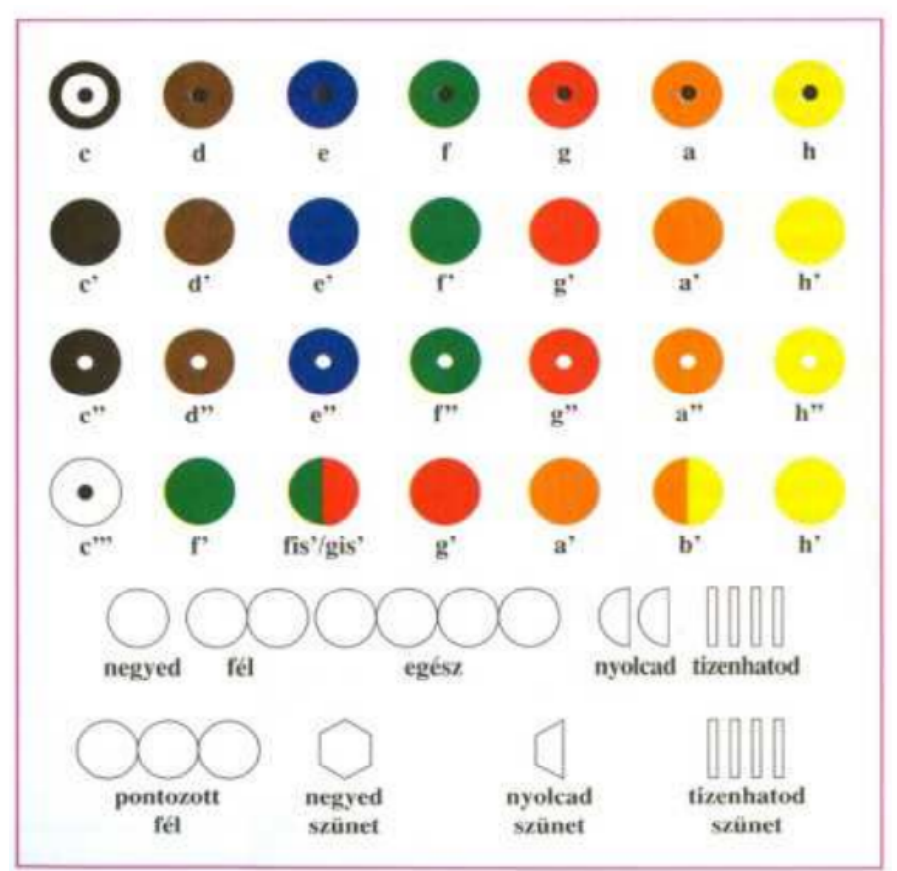

Şekil 1. Ulwila renkli nota sistemi (Bakos, 2014-5)

Ulwila müzik öğretim yaklaşımında notaların süreleri de şekilleri ile birlikte verilmektedir. Birbirine geçmiş dört çember birlik notayı, birbirine geçmiş iki çember ikilik notayı, tek bir çember dörtlük notayı, yarım çember sekizlik notayı, dört dik çubuk ise onaltııı notayı temsil etmektedir. Bu sistemde ayrıca sus değerlerinin de karşılığı bulunmaktadır. Sus işaretleri içi boş, renksiz olarak kullanılmaktadır. Altıgen şekli dörtlük sus, altıgenin yarısından bölünmüş şekli sekizlik, dört dik çubuk onaltılık sus değerlerini temsil etmektedir. Ritim şekilleri ile ikilik sus kullanılmak istendiğinde nota şekillerinde olduğu gibi dörtlük sus değerinin karşılığı olan şekil iki kez yazılmaktadır. Ulwila ritim işaretlerinin nota karşılıklarına Tablo 1'de yer verilmiştir.

Tablo 1. Ulwila ritim şekilleri

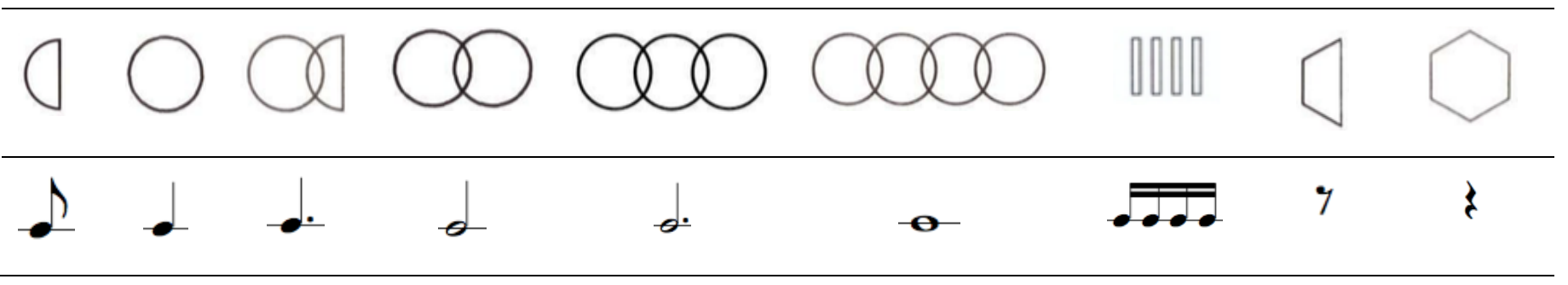


Ullrich'in bu renkli nota sistemini tanıtan, küçük ezgilerden orkestra düzenlemelerine kadar çok sayıda çalışmanın yer aldığı kitapları bulunmaktadır. 1991-1995 yıllarında Ullrich'in kendi yayınevi olan ULWILA Farbklang yayınevi tarafından basılan kitaplar aşağıda sıralanmıştır.

- Tek Sesten Oluşan Şarkılar, Temel Kurs-1

- $\quad$ iki Sesten Oluşan Şarkılar, Temel Kurs-2

- Üç Sesten Oluşan Şarkılar, Temel Kurs-3

- Daha Çok Sesten Oluşan Şarkılar, Temel Kurs-5

- Heinrich Ullrich Tarafından Bestelenen Macarca Şarkılar

- $\quad$ Dizek Üzerinde Temel Nota Kursu 1

- Dizek Üzerinde Temel Nota Kursu 1b

- $\quad$ Dizek Üzerinde Temel Nota Kursu 2

- $\quad$ Dizek Üzerinde Temel Nota Kursu 3

- Dizek Üzerinde Temel Nota Kursu 5a

- $\quad$ Dizek Üzerinde Temel Nota Kursu 5b

- Solo ve Eşlikli Notalar- Cilt 1

- $\quad$ Solo ve Eşlikli Notalar- Cilt 2

- Solo ve Eşlikli Notalar-4

- Akor Çalgıları (Akkordbrett Ve Akkordlaute) İçin Notalar I-1

- Akor Çalgıları (Akkordbrett Ve Akkordlaute) İçin Notalar I-2

- Akor Çalgıları (Akkordbrett Ve Akkordlaute) İçin Notalar I-3

- Akor Çalgıları (Akkordbrett Ve Akkordlaute) İçin Notalar I-4

- Akor Çalgıları (Akkordbrett Ve Akkordlaute) İçin Notalar II-1

- Akor Çalgıları (Akkordbrett Ve Akkordlaute) İçin Notalar II-2

- Akor Çalgıları (Akkordbrett Ve Akkordlaute) İçin Notalar II-3

- Akor Çalgıları (Akkordbrett Ve Akkordlaute) İçin Notalar II-4

- Solo ve Eşlik İçin Noel Şarkıları-1

- Solo ve Eşlik İçin Noel Şarkıları-2

- Solo ve Eşlik İçin Noel Şarkıları-3

- ULWILA Boyama Kitapçı̆̆ı

- Solo ve Eşlik İçin Şarkılar-Boyama 1

- Solo ve Eşlik İçin Şarkılar-Boyama 2 (Ullrich, n.d.a)

Ullrich tek, iki, üç ve daha çok ses için yazmış olduğu temel kurs kitaplarında Ulwila renkli nota sisteminde yazılmış ezgiler bulunmaktadır. Temel Kurs-1 kitabında yer alan ilk ezgi Şekil 2'de yer verilmiştir. Ulwila renkli nota sisteminde ölçü başlarının, şekillerin üzerindeki siyah ters üçgen işaretleri ile belirtildiği görülmektedir.

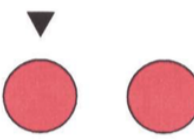

Laßt uns

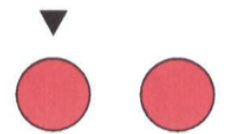

$\sin \quad-$ gen,

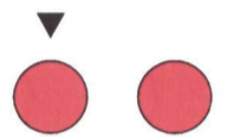

spie - len,

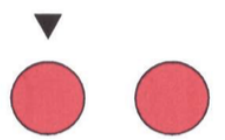

$\tan -$ zen.

Şekil 2. Ulwila renkli nota sisteminde tek ses şarkı örneği (Ullrich, 1995: 3)

Dizek Üzerinde Temel Nota Kursu kitaplarında ilk olarak Ulwila sistemi ile yazılmış şarkının notası bulunmaktadır. Daha sonra kılavuz niteliğinde şarkıda yer alan notaların ve nota sürelerinin tanıtımı yapılarak dizek üzerinde yazılmış notasına yer verilmiştir. Ullrich'in Dizek Üzerinde Temel Nota Kursu 3 kitabında bulunan bir ezgi şekil 3’te gösterilmiştir.

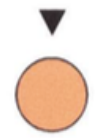

kauft

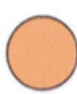

der

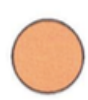

$\mathrm{Pa}$

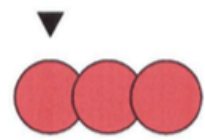

pa,

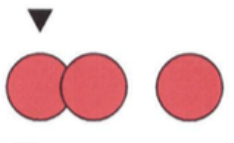

Rin - ge,

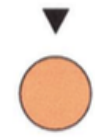

für

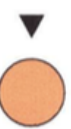

welch

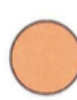

die

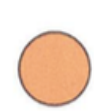

$\mathrm{Ma}$

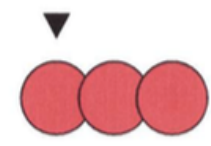

ma.

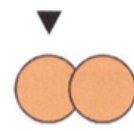

Ket

ten,
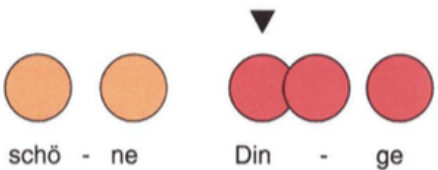

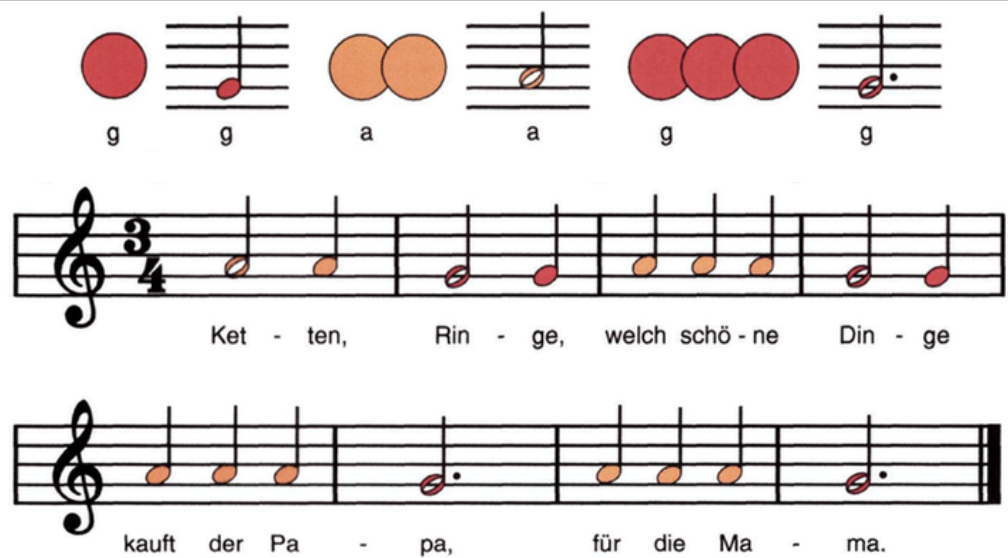

Şekil 3. Dizek üzerinde temel nota kursu kitabından ezgi örneği (Ullrich, 1995: 8,9)

Ullrich'in Solo ve Eşlikli Notalar kitapları incelendiğinde ise soloya eşlik eden çok sesli partisyonların bulunduğu görülmektedir. Solo ve Eşlikli Notalar Kitabı Cilt 2'den müziği W.A. Mozart'a ait olan "In einem kleinen Apfel" (Küçük Bir Elmanın İçinde) şarkısının Ulwila renkli nota sisteminde yazılmış örneği Şekil 4'te yer almaktadır.

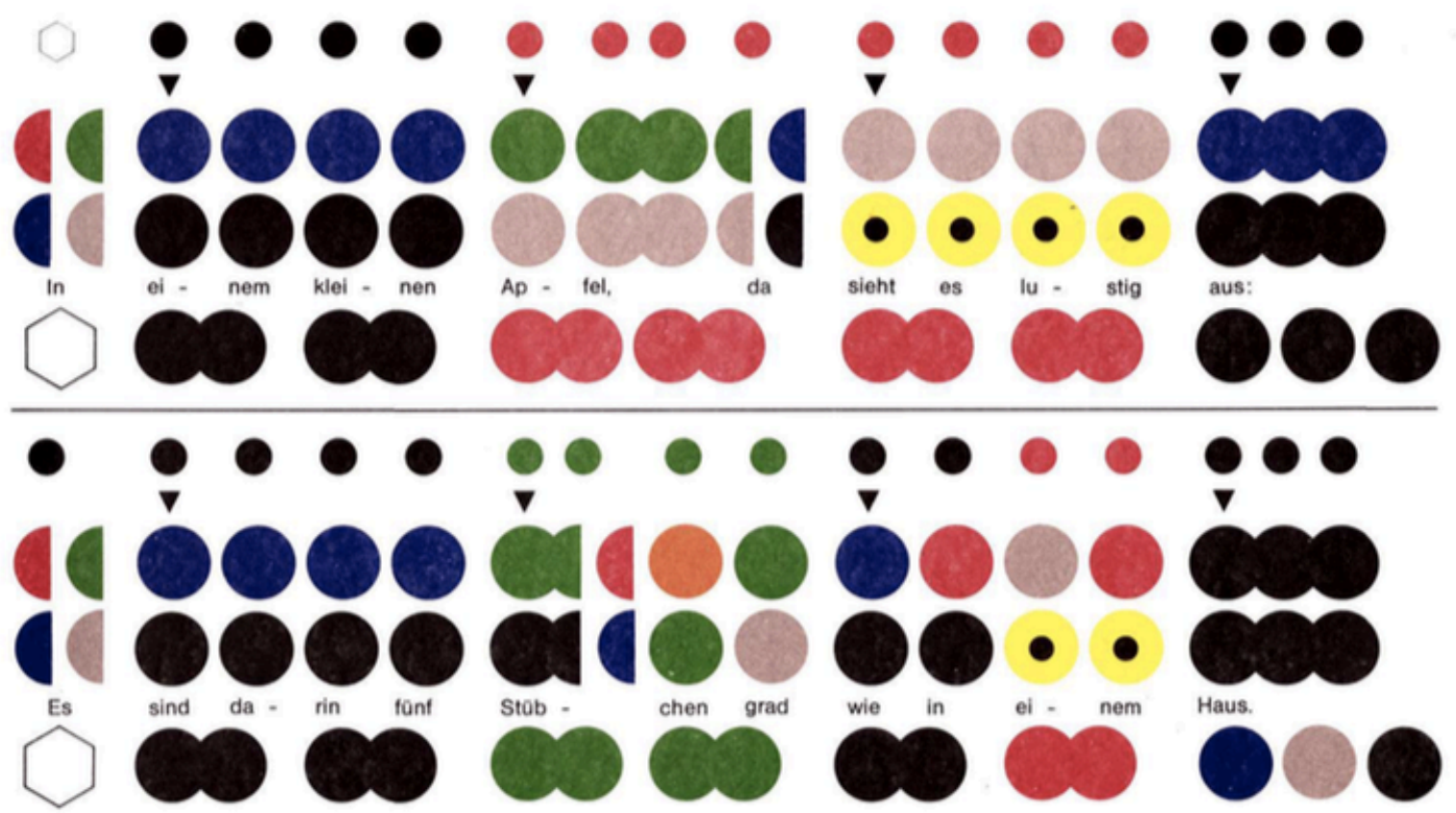

Şekil 4. Ulwila solo ve eşlikli şarkı örneği (Ullrich, 1991: 5)

Ullrich'in Akkordbrett ve Akkordlaute gibi akor çalgıları için düzenlediği notalardan oluşan kitaplarında ise, Ulwila renkli nota sistemi ile birlikte dizek üzerine yazılan nota sistemini birlikte kullanılmıştır. Akor Çalgıları İçin Notalar I-1 kitabından, müziği W.A. Mozart'a ait olan "In einem kleinen Apfel" (Küçük Bir Elmanın İçinde) şarkısının akor çalgılar için yazılmış nota örneğine Şekil 5’te yer verilmiştir.
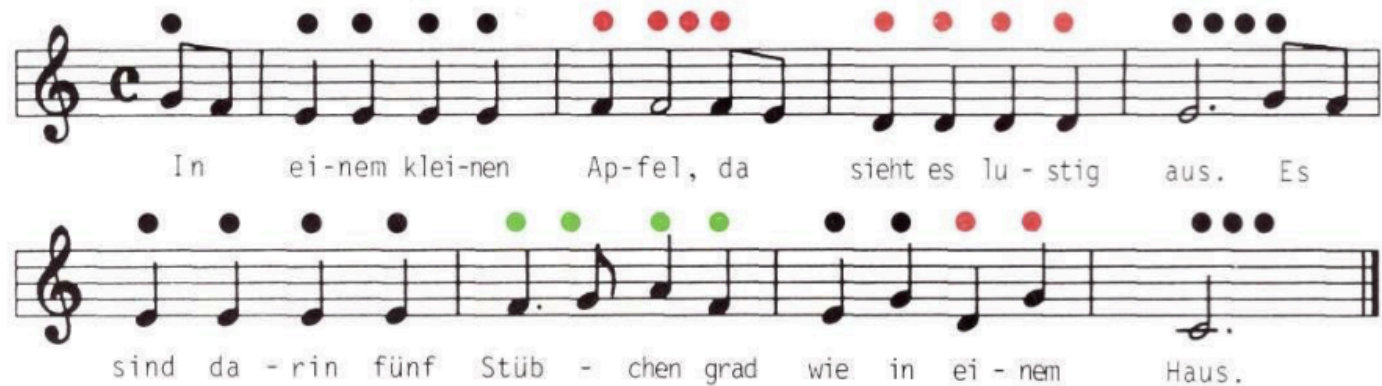


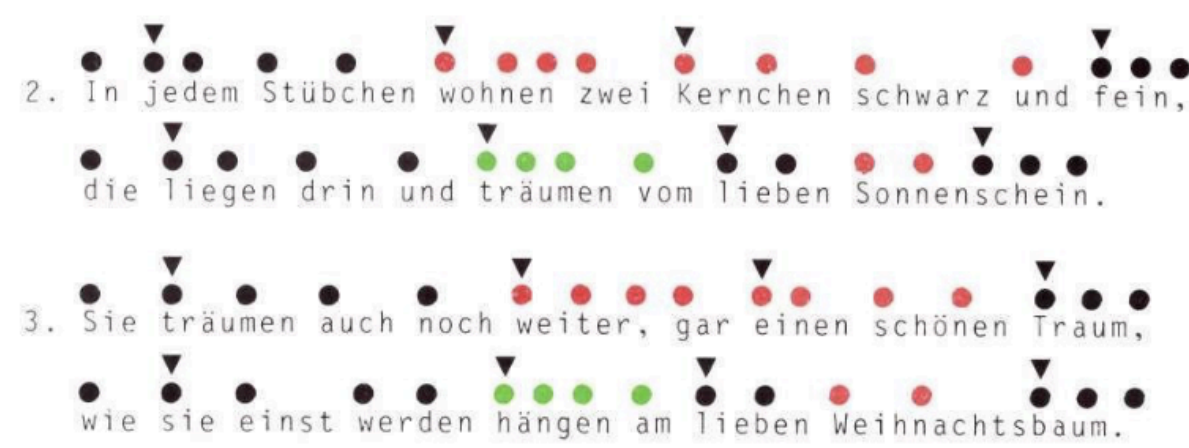

Şekil 5. Akor çalgıları için şarkı örneği (Ullrich, 1991: 7)

\section{Heinrich Ullrich'in Müzik Sisteminde Kullanılan Çalgılar ve Özellikleri}

Ulwila müzik öğretim yaklaşımında kullanılan çalgılar, Orff-Schulwerk yaklaşımında kullanılan çalgılar ile benzerlik göstermektedir. Bu yaklaşımın çalgıları özel geliştirilmiş tuşlu, vurmalı, telli ve benzeri çalgılardır. Renk sistemi çalgılarda da kendini göstermektedir. "Nota sisteminde görülen bu renkler, özel Ulwila çalgılarının tellerinin, borularının ve burgularının yanında da belirtilmiştir. Ullrich'in yöntemine göre çocuklar renklerin isimlerini bile bilmeden bir sesi karşılık gelen rengiyle eşleştirebilir" (Tóth-Bakos, 2016:7). Kullanılan renkli nota sistemi ve çalgılar da bu amaca hizmet edecek şekilde tasarlanmıştır. Bu çalgılardan birkaçı Akkordbrett, Akkordlaute, Bass, Saiten-bassstäbe, Farb-banjo, Mundharmonika, Roehrenglsp, Spießlaute, Steckfloete, Zupfbrett olarak sıralanabilir.

Akor tahtası anlamına gelen Akkordbrett çalgısı, akor çalımları için kullanılmaktadır. Pena kullanılarak tel çekme tekniği ile çalınan Akkordbrett çalgısında renkler, akorları ifade etmektedir. Siyah, Do Majörü; kırmızı, Sol Majörü; kahverengi, Re Majörü; turuncu, La Majörü; yeşil ise Fa Majörü temsil etmektedir. Majör olan bu akor sistemi, akort anahtarı ile akord edilerek minör akorlara da dönüştürülebilir (Manhart, 2007:46). Şekil 6'da Akkordbrett görseline yer verilmiştir.

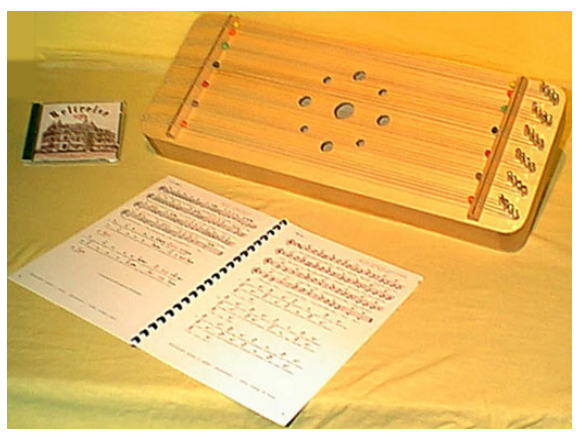

\section{Şekil 6. Akkordbrett (Ullrich, n.d.)}

"Genellikle Ulwila çalgılarının 'kraliçesi' olarak adlandırılan Akkordlaute, Majör (Do Majör) ve minör (la minör) akorlar bulunan dört telli iki kııımdan oluşmaktadır" (Manhart, 2007:48). Tek elle çalınan Akkordbrett çalgısının aksine iki elin de aktif kullanıldığı Akkordlaute' de dört tele hafifçe basılması ile diğer tonaliterdeki majör ve minör akorların çalınması mümkün hale gelmektedir. Sol el renklerin bulunduğu bölümde akorlara basarken sağ el bir pena yardımı veya parmak ile telleri çekerek ses üretilmektedir. Akkordbrett gibi önemli bir eşlik çalgısı olan Akkordlaute'nin görseline Şekil 7'de yer verilmiştir.

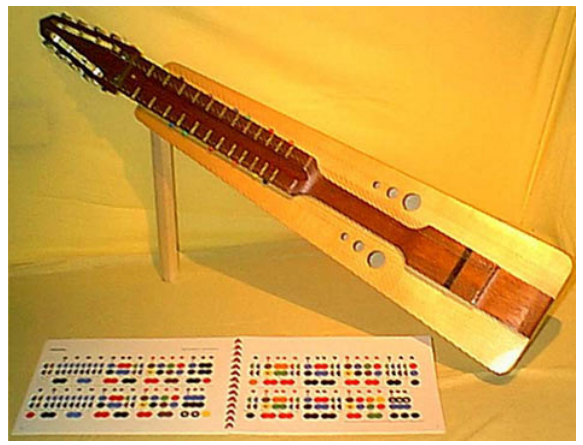

\section{Şekil 7. Akkordlaute (Ullirich, n.d.)}

Görünümü ile mandolin çalgısını andıran Ulwila çalgılarından Bass, Si ve Fa sesi olmak üzere iki telden oluşmaktadır. Bir çalgı grubunda kontrbas çalgııının önemi ile Ulwila çalgıları arasında Bass çalgısının önemi eşdeğer düşünülmektedir. Şekil 8'de görsel örneğine yer verilmiş olan Bass çalgısı üzerinde renkli perdelerin bulunduğu bölüm sol el işaret parmağı ile basılırken sağ el ile gövdeden tel çekilmesi ile ses üretilmektedir. 


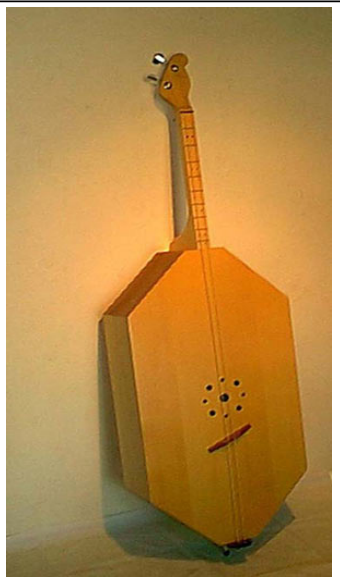

\section{Şekil 8. Bass (Ullrich, n.d.)}

Saiten-bassstäbe, her bir gövdeye bir telin gerilen tahta bloklardan oluşmaktadır. Orff çalgılarında sıklıkla kullanılan tokmak benzeri bir çubuğun keçe kaplanmış türü ile çalınmaktadır. Saiten-bassstäbe çalgısı daha az koordinasyon gerektirdiği için Bass çalgııına göre daha iyi bir alternatif olarak düşünülebilir. Saiten-bassstäbe çalgısının görsel örneğine Şekil 9'da yer verilmiştir.

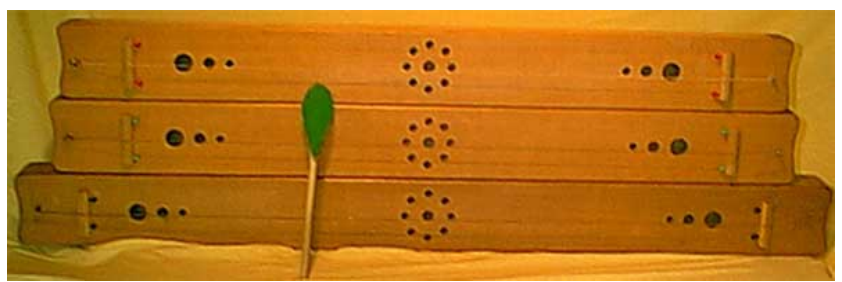

\section{Şekil 9. Saiten-bassstäbe (Ullrich, n.d.)}

Renkli banjo anlamına gelen Farb-banjo, görünümü itibari ile banjo çalgısına oldukça benzemektedir. Akkordbrett ve Akkordlaute gibi eşlik çalgıları ile birlikte solist çalgı olarak kullanılabilmektedir. Sol el parmağının perdelere basması ve sağ el işaret parmağının telleri çekmesi ile çalınan Farb-banjo'da do, sol, do' ve mi' sesleri olmak üzere dört tel bulunmaktadır. Çalgının görseline yer verilen Şekil10'da görüldüğü üzere renkli perdeler ise çalgının sap kısmında bulunmaktadır.

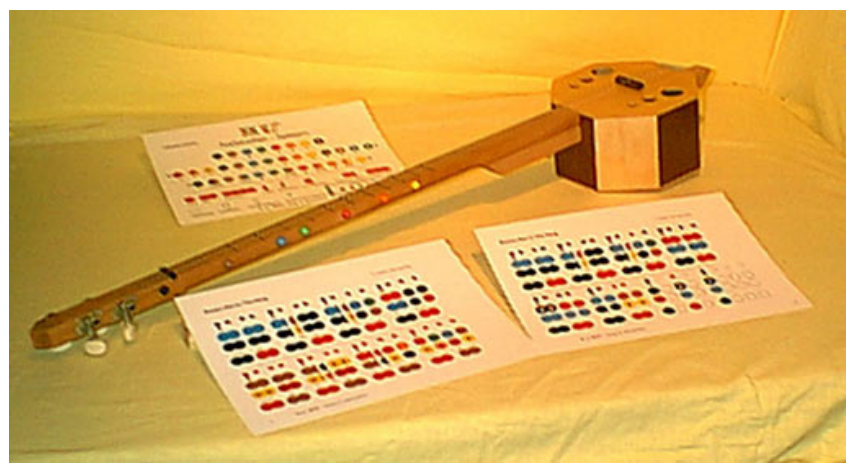

\section{Şekil 10. Farb-banjo (Ullrich, n.d.)}

Ağız mızıkası anlamına gelen Mundharmonika çalgııının yapısı birbirine geçmeli ayarlanabilir borulardan oluşmaktadır. Normal mızıkadan farklı olarak Mundharmonika'da nefesin içe doğru çekilmesi ile değil yalnızca üfleme ile ses üretilebilir. Her bir boruda Ulwila renk sisteminin yer aldığı Mundharmonika, Şekil 11'de görselinde görülmektedir.

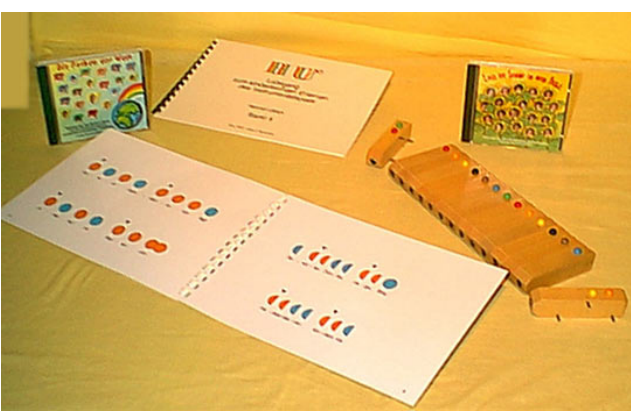

Şekil 11. Mundharmonika (Ullrich, n.d.) 
Orff çalgılarından ksilofon ile benzerliği dikkat çeken Roehrenglsp çalgısı, ksilofonun aksine ahşap düzeneğe geçirilmiş borulardan oluşmaktadır. Ulwila renk sistemi, çalgının ahşap düzenek bölümünde ve 13 borunun her birinde kullanılmıştır. Ksilofon gibi tokmakla çalınan Roehrenglsp çalgısının görsel örneğine şekil 12'de yer verilmiştir.

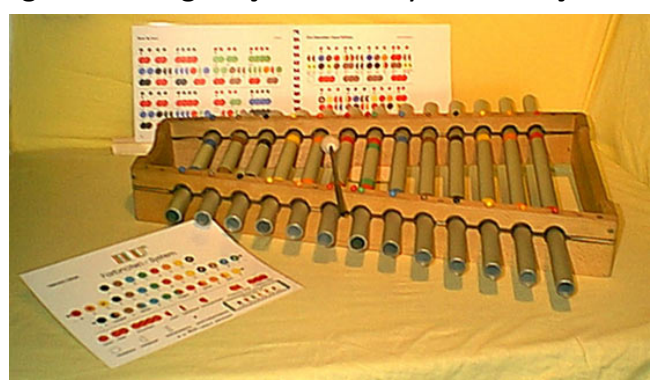

\section{Şekil 12. Roehrenglsp (Ullrich, n.d.)}

Ulwila çalgılarından saplı lavta olarak ifade edilebilen Spießlaute’nin, çalım tekniği itibari ile gitara benzediği söylenebilir. Tek telli bir çalgı olarak sap kısmında renk sistemi yer alan çalgıda bir oktav Do Majör dizi kromatik şekilde çalınabilmektedir. Ayrıca "ses aralığı si'-re"' olan soprano; b-d" olan alto ve B-d' olan tenor olmak üzere Spießlaute çalgısının üç türü bulunmaktadır" (Manhart, 2007:47). Spießlaute'nin örnek görseline Şekil 13'te yer verilmiştir.

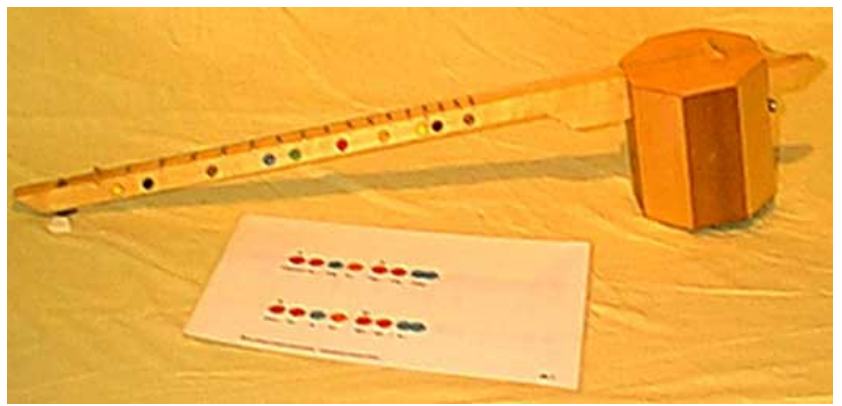

\section{Şekil 13. Spießlaute (Ullrich, n.d.)}

Yapısal olarak Pan flütle oldukça benzerlik gösteren Steckfloete, üflemeyi kolaylaştıran özel ağızlığı ile Pan flütten ayrılmaktadır. Her boruda Ulwila renklerini gördüğümüz Steckfloete'nin ses aralığı sol'-mi'" olan alto ve sol"'- mi"' olan soprano olmak üzere iki türü bulunmaktadır. Nemlenmeyi önlemek adına akçaağaçtan yapılmıştır. Ayrıca boru sayısını isteğe göre belirleyebilmek için basitçe takılıp sökülen bir sisteme sahiptir. Steckfloete'nin ve türlerinin örnekleri Şekil 14'teki görselde bulunmaktadır.

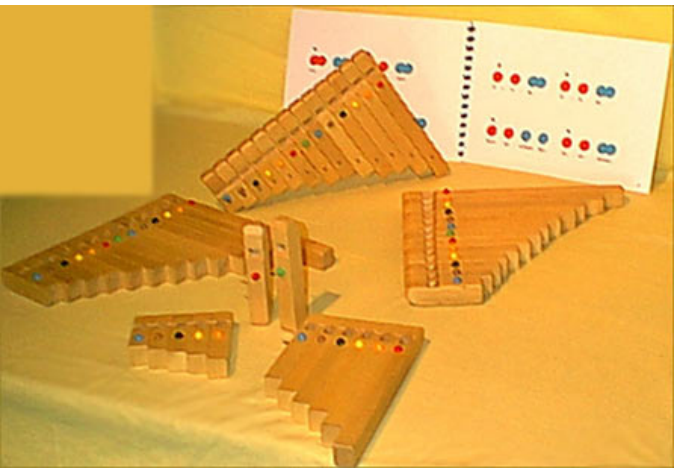

\section{Şekil 14. Steckfloete (Ullrich, n.d.)}

Mızraplı tahta anlamına gelen Zupfbrett, yapısal anlamda bir Alman çalgısı olan Zither'e benzemekle birlikte, onun daha az telli hali olarak tanımlanabilir. Zupfbrett birden çok farklı teknikle çalınabilir. Mızrap kullanarak, telleri parmak yardımı ile çekerek veya Saiten-bassstäbe çalgısında olduğu gibi keçe kaplı tokmak ile tellere vurarak çalmak mümkündür. Soprano, alto, tenor ve bas olmak üzere dört oktav ses aralığını mümkün kılan dört çeşidi bulunmaktadır. Çalgının örnek görseline Şekil 15’te yer verilmiştir. 


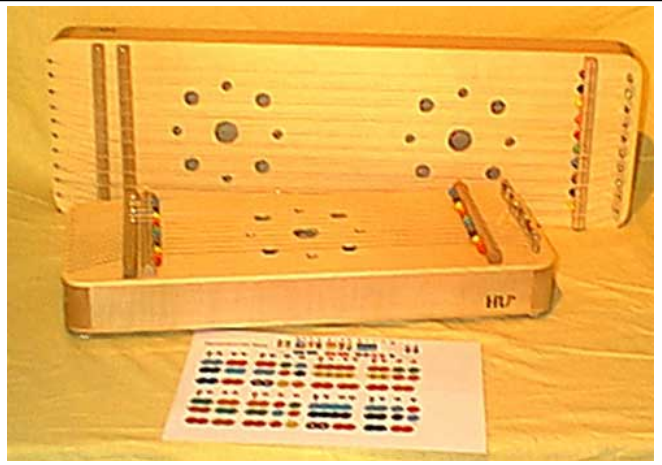

\section{Şekil 15. Zupfbrett (Ullrich, n.d.)}

Yaklaşım gereği notalar bireylerin daha rahat anlayabileceği şekilde renkli olarak çalgılar üzerine yerleştirilmiştir. Çocuklar ile yetişkinler nota öğrenmeyi ve müzik yapmayı bu sayede daha hızlı kavrayabilmektedirler.

Üflemeli çalgıların dışında diğer çalgılar ahşap bir yapıya sahiptir. Günümüzde çalgılar ile gerekli malzemeler Macaristan' da üretilmekte ve Tom Mutter School'da kullanılmaktadır. Bu malzemeler ve çalgıların satışı, dağıtımı yapılmamaktadır. OrffSchulwerk yaklaşımında kullanılan çalgılar ile benzerlik gösterdiğinden Orff çalgıları da Ulwila yaklaşımında kullanılabilmektedir.

\section{Heinrich Ullrich Müzik Sistemini Uygulayan Kurum veya Kuruluşlar}

Ulwila müzik öğretim yaklaşımı Almanya'nın Frankenthal şehrinde bulunan Tom Mutters Schule' de uygulanmaktadır. Ullrich'in kurucusu olduğu bu okulda, müzik eğitimi ve orkestra çalışmaları Ullrich tarafından gerçekleştirilmiştir. Ayrıca Ullrich'in, şefliğini yaptığı okul orkestrası ile 1999 yılında Art Voice Records tarafından çıkarılan Lass Die Sonne In Dein Herz (Güneşi Kalbine Al) isimli bir albümü bulunmaktadır.

Almanya'dan sonra Macaristan'da da bu yaklaşım benimsenerek birçok özel eğitim okulunda uygulanmıştır. Özel eğitim öğretmeni olan Anna Vetõ, 1991 yılında Ulwila yaklaşımını Macaristan'a tanıtmışır. 1995 yılında engelli gençlere ve çocuklara yönelik Ulwila müzik programı kullanılmaya başlanmış, 1997'de ise "A zene mindenkié" (Müzik Herkese Aittir) derneği ile Budapeşte Ulwila Orkestrası kurulmuştur. Bu orkestra 2003 yılında Parafonia adını almışır.

Parafonia Orkestrası, Ulwila müzik eğitimi yaklaşımını temel alarak kurulmuştur. Çocukların ve yetişkinlerin yer aldığı bu orkestra; müzik ile tanışma ve bireyin müziksel gelişimi açısından önem taşımaktadır. Ulwila yaklaşımı ile nota öğrenmek ve müzik yapmak kolay hale getirilmiş ve bireylere çokseslilik öğretimi amaçlanmışır. Okul orkestrasının repertuvarında klasik eserler yanında (Bach, Beethoven, Mozart, Verdi ve Bartok), ulusal müzikler, rock ve gospel eserler de yer almaktadır.

"Kurum bu yaklaşımı benimseyerek öğrencilerin; neşeli, dışa dönük, iletişim becerileri kuvvetli, sosyal ve mental olarak geliş̧̧̧̧ bireyler olmalarını desteklemektedir" (Katalin. 2005). Birlikte müzik yapma fikrinden yola çıkarak kişisel gelişimlerine yardımcı olmayı, müzik yaşantıları ile de başarı hissini tatmalarına yardımcı olmaktadır.

"Orkestra her yıl bir konser etkinliği düzenlemektedir ve eserlerini kayıt ederek albüm satışı gerçekleştirmektedir. Zihinsel engelli çocukların ve gençlerin de müzik eğitimi alabileceği inancından yola çıkarak kurulan bu orkestra 'A zene mindenkié' derneği adı altında çalışmalarını gerçekleştirmekte; bireysel veya gruplara müzik dersleri de vermektedir" (Katalin. 2005).

Ulwila yaklaşımında müzik eğitimi ve orkestra çalışmalarını sürdüren bir diğer eğitimci de Gábor Bajnok'tur "'Dió' Általános Iskola (Dió ilkokulu)'da müzik öğretmeni ve Dió Orkestrası'nın (zihinsel engelli çocuklardan oluşan) şefi olan Gábor Bajnok, 2005 yılından beri her yıl bahar aylarında10-12 özel orkestranın buluşup birlikte performans sergilediği 'Müzik Bahar Şenliği' adında bir festival düzenlemektedir" (Tiszai, 2015).

\section{SONUÇ VE ÖNERILER}

Araştırmada elde edilen bulgular doğrultusunda;

- Özel eğitim ihtiyacı olan bireylerin müzik eğitimlerinin, Ulwila yaklaşımı ve çalgıları ile öğrenilebildiği,

- Öğrencilerin yaş grupları ve öğretmenleri ile birlikte çalışmalar yapması onları daha çok teşvik ettiği,

- Özel eğitim ihtiyacı olan bireylerin çalgı çalması ve müzik eğitimi almasında herhangi bir sorun teşkil etmediği gibi uygun bir yaklaşımın da Ulwila Müzik Eğitimi Yaklaşımı olduğu,

- Ulwila yaklaşımının, özel eğitim alan öğrencilerin müzik eğitiminde Avrupa'da yapılmış ilk çalışmalardan olduğu sonucuna ulaşılmıştır.

Heinrich Ullrich'in geliştirmiş olduğu Ulwila Metodu'nun kullanımına ilişkin elde edilen bu sonuçlar ışığında;

- Ulwila yaklaşımında kullanılan renkli nota sisteminin okul öncesi eğitimde de uygulanabileceği,

- Çalgı yapımı veya temin edilmesi zor olacağından Orff Yaklaşımında kullanılan temel çalgıların bu yaklaşıma uyarlanması uygun olacağı, 
- Grup ile hareket edebilme, çoksesli müzik deneyimi ve başarı hissi gibi davranışların bu yaklaşım ile kolaylıkla kazandırılabileceği düşünüldüğünden özel eğitim ve erken yaş müzik eğitiminde bu yaklaşımın kullanılması önerilmektedir.

\section{Etik Kurul Onay Bilgileri}

Yapılan bu çalışmada "Yükseköğretim Kurumları Bilimsel Araştırma ve Yayın Etiği Yönergesi” kapsamında uyulması belirtilen tüm kurallara uyulmuştur. Yönergenin ikinci bölümü olan "Bilimsel Araştırma ve Yayın Etiğine Aykırı Eylemler" başlığı altında belirtilen eylemlerden hiçbiri gerçekleştirilmemiştir. Doküman inceleme yolu ile verilere ulaşılan bu araştırmada etik kurul izni ve/veya yasal/özel izin alınması gerekmemiştir.

\section{KAYNAKÇA}

Bakos, A. (2014). Zenetanulás Színesen - A Színes Kotta Módszer Magyar Nyelvű Kiadványai. Retrieved May 22, 2017, from https://www.parlando.hu/2014/2014-3/Bakos_Anita_Zenetanulas.pdf.

Eisenhardt, K. M. (1989). Building Theories from Case Study Research. The Academy of Management Review, 14(4), doi: $10.2307 / 258557$

Karataş, Z. (2015). Sosyal bilimlerde nitel araştırma yöntemleri. Manevi Temelli Sosyal Hizmet Araştırmaları Dergisi 1(1)

Katalin, E. (2005). The Music Education of Mentally Disabled Children With The Help Of The Colored Score System. Retrieved December 22, 2016, from http://www.parafonia.hu/index.php?option=com_content\&task=view\&id=29\&Itemid=41.

Manhart, J. (2007). MusikFarbenSpiel: Musizieren mit Menschen mit geistiger Behinderung. Konzeption, Durchführung und Evaluation einer Unterrichtssequenz Fakultät für Psychologie und Pädagogik Abteilung für Präventions-Integrations- und Rehabilitationsforschung: Universität München.

Şentürk, N. (1998). Müzik Eğitiminde Yeni Yaklaşımlar. 5. Antalya Semineri, Ted Ankara Koleji.

Tıkaç, S. (2015). Nitel veri analiz programlarının veri analizinde kullanımı: Nvivo'ya bir bakış. F.N. Seggie \& F. Bayyurt Nitel araştırma: Yöntem, teknik, analiz ve yaklaşımlar. Ankara: Anı.

Tiszai, L. (2015). The Precursory Model: ULWILA. Retrieved December 13, 2019, from https://consonante.eoldal.hu/cikkek/theprecursory-model--ulwila.html.

Tóth-Bakos, A. (2013). The Ulwila Method Color Score System. Tanítóképző Tanszék. Retrieved December 2, 2016, https://www.researchgate.net/publication/266781590_Az_Ulwila_szines_kotta_modszer_The_Ulwila_method_color_ score_system

Tóth-Bakos, A. (2016). Music Education And Music Therapy. INTED2016 Proceedings. doi: 10.21125/inted.2016.0135

Ullrich, H. (1995). Ulwila Farbklang, Grandkurs 3 B. Germersheim: ULWILA-Verlag.

Ullrich, H. (1995). Ulwila Farbklang, Grandkurs 1 A. Germersheim: ULWILA-Verlag.

Ullrich, H. (1991). Ulwila Farbklang, Spiel- und Singbuch Band 2. Germersheim: ULWILA-Verlag.

Ullrich, H. (1991). Liederbuch für Akkordbrett und Akkordlaute Band 1. Germersheim: ULWILA-Verlag.

Ullrich, H. (n.d.). Ulwila Instruments, Retrieved June 7, 2017, from http://www.hu-s.de/Seiten/Instrumente.htm

Ullrich, H. (n.d.a). ULWILA Kották. Retrieved October 18, 2019, from http://www.downalapitvany.hu/node/1040.

Yıldırım, A., \& Şimşek, H. (2016). Sosyal bilimlerde nitel araştırma yöntemleri(10th ed.). Ankara: Seçkin Yayıncılık. 